\title{
Effect of Fluconazole on Phagocytic Response of Polymorphonuclear Leukocytes in a Rat Model of Acute Sepsis
}

\author{
Haseeb Ahmad Khan \\ Department of Biochemistry, College of Science, King Saud University, Riyadh 11451, Saudi Arabia; haseeb@ksu.edu.sa
}

Received 1 November 2004; accepted 16 November 2004

\begin{abstract}
Recently, fluconazole (FLZ) has been shown to improve survival and reduce multiorgan failure in experimental and clinical septic shock. The mechanism by which FLZ affords protection against sepsis remains obscure. This study examines the effect of FLZ on phagocytic activity of polymorphonuclear leukocytes (PMNs) in a rat model of septic shock by inducing fecal peritonitis in male Wistar rats using intraperitoneal instillation $(1 \mathrm{~mL} / \mathrm{kg})$ of fecal suspension in saline $(1: 1 \mathrm{w} / \mathrm{v})$. Sham control rats received sterile fecal suspension and vehicle treatment. FLZ was administered in the doses of $0,3,10$, and $30 \mathrm{mg} / \mathrm{kg}$ by gavage 30 minutes before fecal instillation. The samples of peritoneal fluid were collected 8 hours following fecal inoculation for the evaluation of phagocytic response of PMNs using zymosan-induced luminol-dependent chemiluminescence (CL). Fecal peritonitis caused massive infiltration of PMNs in the peritoneal cavity (ANOVA $F_{4,45}=6.322, P<.001$ ). Although FLZ reduced the infiltration of PMNs, this effect was neither significant nor dose dependent. The actual CL response was significantly higher in the peritoneal fluid of rats subjected to peritonitis, which was significantly and dose-dependently attenuated by FLZ treatment (ANOVA $F_{4,45}=11.048, P<.001$ ). Normalization of CL response for 1000 PMNs revealed that FLZ dose-dependently albeit insignificantly reduced the activity of PMNs. The high dose of FLZ caused 2.29-fold decrement in the area under curve (AUC) pertaining to cumulative CL response. The findings of this study suggest that FLZ protects rats against septic shock by inhibiting PMN-mediated inflammatory cascade without compromising their phagocytic activity.
\end{abstract}

\section{INTRODUCTION}

Sepsis and its sequelae are often lethal and considered to be the leading causes of mortality in intensive care units $[1,2]$. The cascade of events initiating from infection to septic shock and multiorgan failure is poorly understood. Polymorphonuclear leukocytes (PMNs) are the first line of defense against foreign antigens. Effective host defense against bacterial infection depends on the recruitment and activation of PMNs that localize, kill, and clear the pathogens $[3,4]$. On the other hand, massive inflammatory reaction resulting from uncontrolled sequestration and prolonged activation of PMNs could be potentially deleterious and has largely been implicated in sepsis-mediated multiorgan dysfunction $[5,6,7,8]$. Thus, PMNs (neutrophils and macrophages) could be regarded as dual-edged weapons, their controlled migration and optimal activity being essential for beneficial effects $[4,9,10]$. Therapeutic strategies to attenuate excessive acute inflammatory responses without compromising essential host defense mechanisms would logically benefit in preventing neutrophil-mediated organ damage in septic shock $[11,12]$.
The immunomodulating feature of azole antifungal drugs is a known fact $[13,14]$. Fluconazole (FLZ) is a well-tolerated antifungal drug with a demonstrated ability to reversibly penetrate into human PMNs [15]. Recently, FLZ has been shown to improve survival and reduce multiorgan damage in experimental [16] and clinical septic shock [17]. Since FLZ has no inherent antibacterial properties, its beneficial effects in bacteremia have been attributed to its action on the modulation of neutrophils sequestration and activation [17]. However, the findings of earlier studies regarding the effect of FLZ on the phagocytic response of PMNs are controversial. Only few studies have reported enhanced bactericidal activity of PMNs in presence of FLZ [18, 19]. Even FLZinduced increase in the phagocytosis and intracellular killing of candida have been linked to its direct effect on yeast rather than on phagocytes [19]. On the other hand, many investigators observed that FLZ did not affect the phagocytic activity of PMNs $[13,20,21,22,23,24,25]$. It is therefore intriguing to better understand the nature of interaction between FLZ and PMNs in sepsis, and the present investigation is an attempt in this direction. 
TABLE 1. Effect of fluconazole (FLZ) on luminol-dependent chemiluminescence response of phagocyting leukocytes in the peritoneal fluid of rats with septic shock.

\begin{tabular}{l|c|cc|cc}
\hline \multirow{2}{*}{ Treatment group } & $\begin{array}{c}\text { Leukocytes count in } \\
\text { peritoneal fluid per } \\
\mathrm{mm}^{3}\end{array}$ & \multicolumn{2}{|c}{ RLU (integral value) } & \multicolumn{2}{c}{ RLU (peak value) } \\
\cline { 3 - 6 } & $\begin{array}{c}\text { Per } 500 \mathrm{~nL} \\
\text { peritoneal fluid }\end{array}$ & $\begin{array}{c}\text { Per 1000 } \\
\text { leukocytes }\end{array}$ & $\begin{array}{c}\text { Per 500 nL } \\
\text { peritoneal fluid }\end{array}$ & $\begin{array}{c}\text { Per 1000 } \\
\text { leukocytes }\end{array}$ \\
\hline Control (sham) & $9440 \pm 780.2$ & $6.67 \pm 3.64$ & $1.16 \pm .57$ & $8.40 \pm 3.10$ & $1.61 \pm 0.47$ \\
FP & $27590 \pm 3007.2 \#$ & $276.94 \pm 39.99 \#$ & $21.21 \pm 2.97 \#$ & $188.30 \pm 25.19 \#$ & $14.42 \pm 1.81 \#$ \\
FP + FLZ 3 & $23730 \pm 3397.6$ & $208.60 \pm 30.85$ & $18.23 \pm 2.33$ & $140.40 \pm 19.33$ & $12.28 \pm 1.42$ \\
FP + FLZ 10 & $19580 \pm 2948.7$ & $164.86 \pm 28.24^{*}$ & $17.85 \pm 2.39$ & $110.80 \pm 19.28^{*}$ & $12.00 \pm 1.61$ \\
FP + FLZ 30 & $21630 \pm 2589.3$ & $144.78 \pm 33.78^{* *}$ & $13.06 \pm 2.94$ & $97.70 \pm 23.25^{* *}$ & $8.87 \pm 2.05$ \\
\hline
\end{tabular}

\# denotes $P<.001$ versus control group, ${ }^{*} P<.05$, and ${ }^{* *} P<.01$ versus FP group using Dunnett's multiple comparison test. RLU (relative light unit) is an arbitrary unit of chemiluminescence measurement.

\section{MATERIALS AND METHODS}

\section{Animals}

Adult male Wistar rats were housed in a temperaturecontrolled room maintained on 12-hour light/dark cycles. The standard laboratory food and water were freely available ad libitum except an overnight fasting before induction of experimental sepsis.

\section{Drug and dosing}

Animals were divided into 5 groups of 10 animals each. FLZ was administered orally in the doses of $0,3,10$, and $30 \mathrm{mg} / \mathrm{kg}$ body weight, 30 minutes before fecal inoculation. This dose regimen was selected on the basis of our earlier study [16]. Control rats received sham surgery and vehicle treatment.

\section{Induction of sepsis in rats}

A fecal peritonitis (FP) model was used to induce acute sepsis in rats [26]. Homogeneous fecal suspension was prepared by dissolving fresh feces $(1: 1 \mathrm{w} / \mathrm{v}$ in normal saline) obtained surgically from the caecum of nonfasted healthy rats, and used within 2 hours. A small incision was made in the abdomen of ether-anesthetized rats for intraperitoneal instillation of fecal suspension at a dosage of $1 \mathrm{~mL} / \mathrm{kg}$ body weight of animals. Control animals received preautoclaved fecal suspension. The wound was closed aseptically and animals returned to home cages. The specimens of peritoneal fluid were collected 8 hours following fecal inoculation. The samples were diluted (100 folds) in Hank's balanced salt solution (HBSS) containing $0.1 \%$ gelatin and promptly analyzed.

\section{Measurement of phagocytosis}

A sensitive procedure based on zymosan-induced luminol-enhanced chemiluminescence (CL) was used to measure phagocytic response of leukocytes [27]. Fifty microliters of prediluted peritoneal fluid samples were mixed with $150 \mu \mathrm{L}$ of reaction mixture $\left(4 \times 10^{-4} \mathrm{M}\right.$ luminol + $50 \mu \mathrm{g}$ opsonized zymosan $+0.1 \%$ gelatin in HBSS) in the well of an opaque cliniplate (Labsystems, Finland).
The CL signal produced by phagocytosing leukocytes was measured at $37^{\circ} \mathrm{C}$ in a luminometer (Model Luminoskan RT, Labsystems). Thirty cycles of measurements using 5-second counting time and 70-second interval time were performed for each sample. The CL intensity was expressed as relative light unit (RLU). Leukocytes were counted in all the samples using a haemocytometer.

The CL response (actual or normalized) has been reported as peak value (highest signal among 30 measurements) and integral value (integration of all the signals for 30-minute measurement time). The actual CL response corresponds to $50 \mu \mathrm{L}$ of 100 -fold diluted peritoneal fluid sample (equivalent to $500 \mathrm{~nL}$ of peritoneal fluid), irrespective of the number of leukocytes within the sample. The normalized CL (per 1000 leukocytes) was used to compare phagocytic activity of the leukocytes in different treatment groups. The area under curve (AUC) was measured (in triplicate) using the public domain image processing and analysis program developed at the National Institute of Health, USA. The PC version of this program, known as Scion Image, is available on http://www.scioncorp.com for free download from Scion, Md, USA.

\section{Statistical analysis}

Data were analyzed by one-way analysis of variance (ANOVA) followed by Dunnett's multiple comparison test. Pearson's test was used for parametric correlations. The statistical significance was defined by $P<.05$.

\section{RESULTS}

\section{Leukocyte count}

The leukocyte count was significantly increased in the peritoneal fluid of rats subjected to FP (27590 \pm $\left.3007 \mathrm{~mm}^{3}\right)$ as compared to sham control rats $(9440 \pm$ $780 \mathrm{~mm}^{3}$ ) $\left(\right.$ ANOVA $\mathrm{F}_{4,45}=6.322, P<.001$ ). Pretreatment with FLZ attenuated leukocyte count in the peritoneal fluid, however this effect was neither dose dependent nor significant (Table 1). 

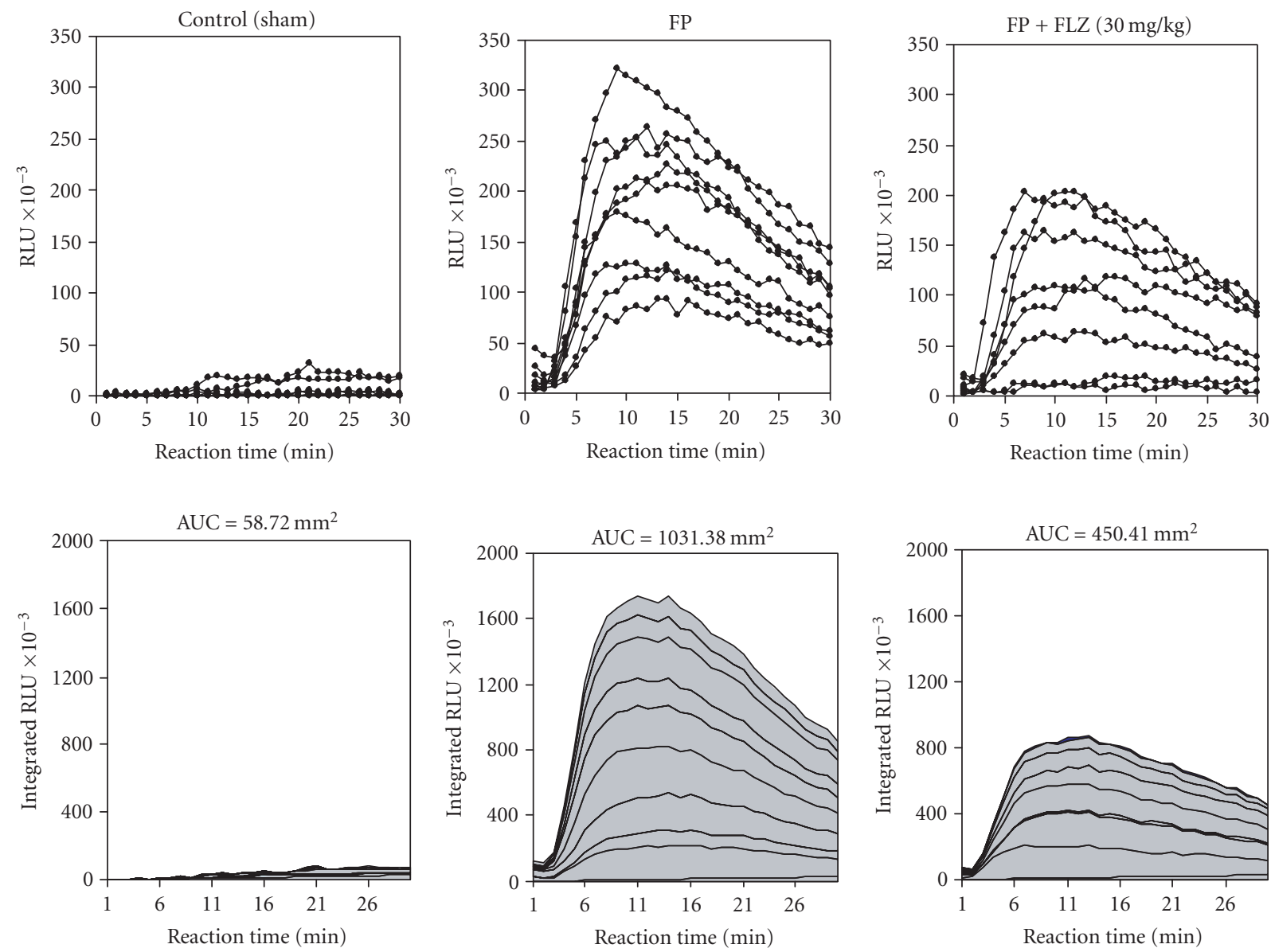

FIGURE 1. Real-time chemiluminescence (CL) signals from individual samples showing the effect of fluconazole (FLZ) on phagocytic activity of leukocytes in the peritoneal fluid $(500 \mathrm{~nL})$ of rats with fecal peritonitis (upper-panel line graphs). Areas under curves were used to display cumulative representation of all the samples and to measure area under curve (AUC) (lower panel). $x$-axes show the measurement time of each sample in the luminometer.

\section{Actual CL response (effective phagocytosis)}

Both integral and peak CL responses (RLUs) were significantly higher in peritonitis group as compared to sham control (Table 1). Administration of FLZ significantly and dose-dependently attenuated the integral (ANOVA $\mathrm{F}_{4,45}=11.048, P<.001$ ) and peak (ANOVA $\mathrm{F}_{4,45}=$ $11.345, P<.001)$ CL responses (Table 1 ). The representative real-time CL signals for control and FP with or without FLZ $(30 \mathrm{mg} / \mathrm{kg})$ groups are shown in Figure 1. The AUC of peritonitis group $\left(1031.38 \pm 16.31 \mathrm{~mm}^{2}\right)$ was 17.56 -fold greater than sham control $\left(58.72 \pm 3.12 \mathrm{~mm}^{2}\right)$. Treatments of rats with FLZ $(30 \mathrm{mg} / \mathrm{kg})$ markedly reduced (2.29-fold) the AUC as compared to peritonitis alone group (Figure 1, lower panel).

\section{Normalized CL response (leukocyte activity)}

The normalization of CL to 1000 leukocytes showed significantly high phagocytic response in peritonitis group as compared to sham control (Table 1). Both inte- $\operatorname{gral}\left(\right.$ ANOVA F $\left._{4,45}=10.754, P<.001\right)$ and peak (ANOVA $\left.\mathrm{F}_{4,45}=10.164, P<.001\right)$ normalized RLUs were significantly higher in the peritonitis alone group. Pretreatment with FLZ dose-dependently reduced the normalized CL responses; however, these effects failed to reach the significance level (Table 1).

\section{Correlation between integral and peak RLUs}

A highly significant correlation (correlation coefficient, $\mathrm{R}=0.995, P<.001$ ) was observed between integral and peak CL responses, irrespective of the treatments administered (Figure 2).

\section{Correlation between leukocyte count and integral RLUs}

The plot of leukocyte count versus integral RLUs is shown in Figure 3. The correlation was statistically significant $(\mathrm{R}=0.693, P<.001)$; however, the data points from various treatment groups appeared staggered around the trend line (Figure 3). 


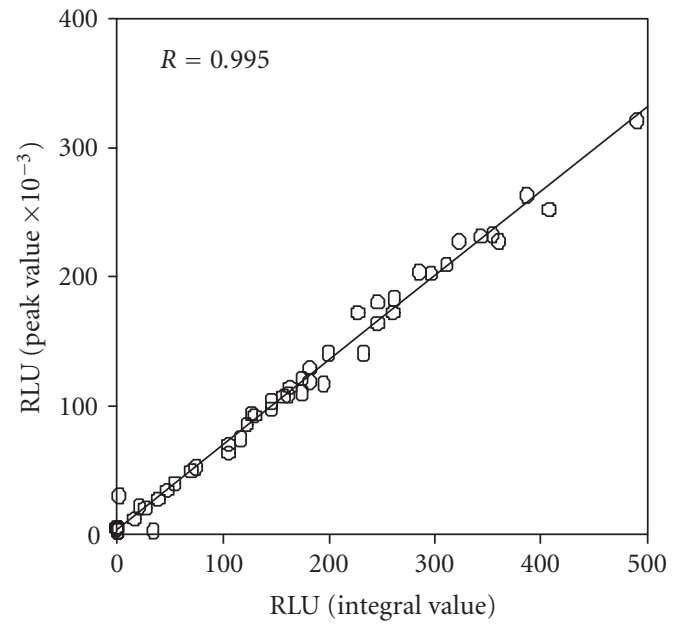

Figure 2. Correlation between the two parameters used to measure chemiluminescence $(\mathrm{CL})$ response of phagocyting leukocytes. Peak value represents the maximal signal intensity among the 30 measurement points, whereas the integral value is the total integration of CL signals for a 30-minute period.

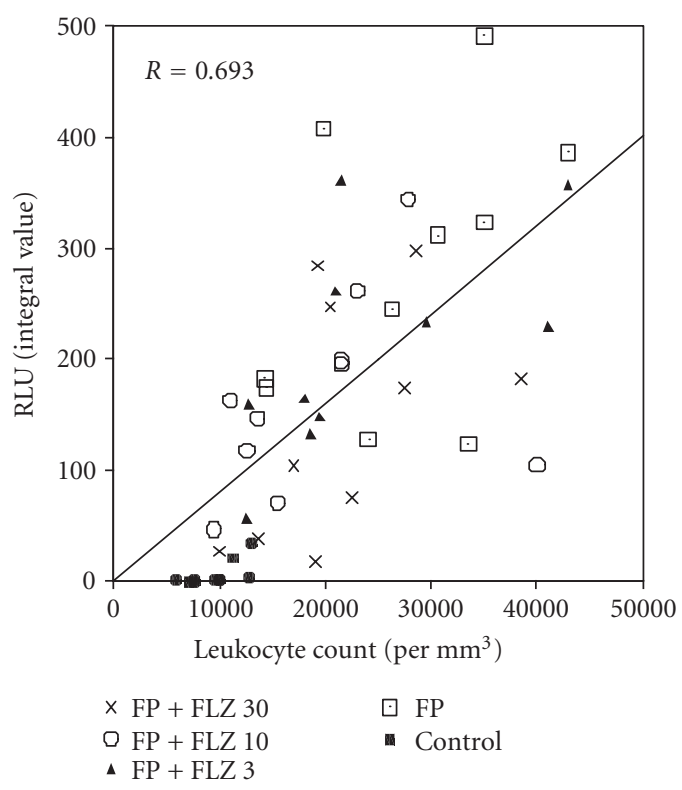

FIGURE 3. Correlation between chemiluminescence signal and leukocyte count in the peritoneal fluid samples.

\section{DISCUSSION}

Fecal peritonitis caused massive infiltration of PMNs in peritoneum (Table 1), which is in accordance with our earlier study [28]. Administration of FLZ insignificantly reduced the sequestration of PMNs to the infectious focus. PMNs migration into the peritoneal cavity in response to FP is an important mechanism of host defense against bacterial invasion as the exudative
PMNs localize and contain infection by phagocytizing and killing bacteria $[29,30,31]$. The migrated PMNs in the peritonitis group showed a highly significant upregulation of their phagocytic activity as compared to sham control (Table 1, Figure 1). Although resting PMNs (neutrophils) consume little $\mathrm{O}_{2}$, their activation involves a marked increase in $\mathrm{O}_{2}$ uptake, often known as "respiratory burst" that results in the production of potentially toxic reactive oxygen species (ROS) [32,33]. The upsurge in $\mathrm{O}_{2}$ uptake is associated with the activation of an enzymatic process that oxidizes NADPH to $\mathrm{NADP}^{+}$, the electron transfer being used to reduce $\mathrm{O}_{2}$ into superoxide radical $\left(\mathrm{O}_{2}^{-}\right)$that further reacts with $\mathrm{H}_{2} \mathrm{O}_{2}$ to produce hydroxyl radical $\left(\mathrm{OH}^{-}\right)$[34]. An enzyme, myeloperoxidase (MPO) is released from activated neutrophils that form hypochlorite $(\mathrm{HOCl})$ after reaction with $\mathrm{H}_{2} \mathrm{O}_{2}$ and $\mathrm{Cl}^{-}$. Activated neutrophils and macrophages are also able to release nitric oxide that combines with $\mathrm{O}_{2}^{--}$to produce peroxynitrile $\left(\mathrm{ONOO}^{-}\right)$[35]. All these ROS have a tendency to produce CL in presence of luminol $[36,37,38]$. Therefore, a high CL signal from migrated PMNs during sepsis indicates excessive generation of ROS that might trigger pathways for host damage [39, 40, 41]. The deleterious effects of ROS are limited by antioxidant defense systems. Increased production of ROS and decreased antioxidant status have been reported in septic shock patients [42, 43, 44, 45].

It is widely accepted that the multiple organ dysfunction is a consequence of generalized inflammatory reaction whereas infection per se triggers these pathways $[6,46]$. The natural resolution of acute inflammation involves bulk clearance of extravasated inflammatory cells in an ordered manner [47]. However, an imbalance between the clearance and infiltration of PMNs and/or disruption of equilibrium between bacterial load and extent of phagocytosing PMNs could be deleterious to host cells. Recent studies have shown that agents with antiinflammatory and/or antioxidant properties significantly protect against experimental $[48,49,50,51,52]$ and clinical septic shock $[53,54]$.

Administration of FLZ significantly and dosedependently reduced the CL response of PMNs in the rats with septic shock (Table 1). On the other hand, the normalized CL values (per 1000 leukocytes) showed that the activity of PMNs is only insignificantly affected by FLZ, which is supported by earlier findings $[13,20,21,22,23,24,25]$. Taken together, these observations suggest that FLZ effectively counteracts excessive ROS generation by PMNs without significantly altering their functionality. The effect of FLZ on controlling the ROS formation by activated PMNs is further evidenced by more than $50 \%$ reduction of AUC in FLZ $(30 \mathrm{mg} / \mathrm{kg})$ group as compared to vehicle-treated rats (Figure 1). The correlation between integral and peak CL responses was independent of treatment groups, suggesting a direct relation between the activity of PMN and sustained production of ROS (Figure 2). Although the correlation analysis between PMNs count and CL response showed 
a positive trend, data points from various treatment groups appeared staggered (Figure 3 ). This within-group variation may be attributed to different magnitudes of immunity in animals. However, this finding points towards the usefulness of individual assessment of septic shock patients with regard to PMNs counts and activity for selecting the effective dose regimen of FLZ.

In conclusion, the protective effects of FLZ in experimental sepsis may be attributed to the inhibition of ROSmediated proinflammatory cascade without compromising effective pathogen clearance. However, the relevance of these findings with human septic shock remains unclear and warrants further clinical study.

\section{REFERENCES}

[1] Bone RC, Grodzin CJ, Balk RA. Sepsis: a new hypothesis for pathogenesis of the disease process. Chest. 1997;112(1):235-243.

[2] Singer M. Management of multiple organ failure: guidelines but no hard-and-fast rules. J Antimicrob Chemother. 1998;41 (suppl A):103-112.

[3] Ikeda S, Saito H, Fukatsu K, et al. Dietary restriction impairs neutrophil exudation by reducing CD11b/CD18 expression and chemokine production. Arch Surg. 2001;136(3):297-304.

[4] Mercer-Jones MA, Heinzelmann M, Peyton JC, Wickel D, Cook M, Cheadle WG. Inhibition of neutrophil migration at the site of infection increases remote organ neutrophil sequestration and injury. Shock. 1997;8(3):193-199.

[5] Lowell CA, Berton G. Resistance to endotoxic shock and reduced neutrophil migration in mice deficient for the Src-family kinases Hck and Fgr. Proc Natl Acad Sci USA. 1998;95(13):7580-7584.

[6] Goris RJ, te Boekhorst TP, Nuytinck JK, Gimbrere JS. Multiple-organ failure. Generalized autodestructive inflammation? Arch Surg. 1985;120(10):1109-1115.

[7] Carey PD, Jenkins JK, Byrne K, et al. Neutrophil short-lived oxidant production: enhancement following onset of sepsis-induced lung injury. Circ Shock. 1992;36(4):256-264.

[8] Karima R, Matsumoto S, Higashi H, Matsushima K. The molecular pathogenesis of endotoxic shock and organ failure. Mol Med Today. 1999;5(3):123-132.

[9] Wagner JG, Roth RA. Neutrophil migration during endotoxemia. J Leukoc Biol. 1999;66(1):10-24.

[10] Workman ML. The immune system: your defensive partner and offensive foe. AACN Clin Issues Crit Care Nurs. 1993;4(3):453-470.

[11] Jaeschke H, Smith CW. Mechanisms of neutrophilinduced parenchymal cell injury. J Leukoc Biol. 1997;61(6):647-653.

[12] Clatworthy MR, Smith KG. FcgammaRIIb balances efficient pathogen clearance and the cytokinemediated consequences of sepsis. J Exp Med. 2004;199(5):717-723.
[13] Drummond DC, Wong CW, Whitman LM, McCormack JG. The effects of amphotericin B, fluconazole and miconazole on neutrophil and lymphocyte function in a guinea pig model. J Antimicrob Chemother. 1995;36(2):375-384.

[14] Di Francesco P, Gaziano R, Casalinuovo IA, Palamara AT, Favalli C, Garaci E. Antifungal and immunoadjuvant properties of fluconazole in mice immunosuppressed with morphine. Chemotherapy. 1997;43(3):198-203.

[15] Pascual A, Garcia I, Conejo C, Perea EJ. Uptake and intracellular activity of fluconazole in human polymorphonuclear leukocytes. Antimicrob Agents Chemother. 1993;37(2):187-190.

[16] Tariq M, Moutaery AA, Arshaduddin M, Khan HA, Price Evans DA, Jacobs S. Fluconazole attenuates lung injury and mortality in a rat peritonitis model. Intensive Care Med. 2003;29(11):2043-2049.

[17] Jacobs S, Price Evans DA, Tariq M, Al Omar NF. Fluconazole improves survival in septic shock: a randomized double-blind prospective study. Crit Care Med. 2003;31(7):1938-1946.

[18] Zervos EE, Bass SS, Robson MC, Rosemurgy AS. Fluconazole increases bactericidal activity of neutrophils. J Trauma. 1996;41(1):10-14.

[19] Tullio V, Cuffini AM, De Leo C, Perrone F, Carlone NA. Interaction of Candida albicans, macrophages and fluconazole: in vitro and ex vivo observations. J Chemother. 1996;8(6):438-444.

[20] Baldauf C, Adam D. Influence of fluconazole on phagocytosis, oxidative burst and killing activity of human phagocytes. Using a flow cytometric method with whole blood. Eur J Med Res. 2000;5(10):455459.

[21] Velert MM, Cabrera E, Orero A, Peman J, Canton E. Effect of fluconazole and itraconazole on human polymorphonuclear leukocyte oxidative metabolism and phagocytosis. Rev Esp Quimioter. 1998;11(1):70-74.

[22] Odds FC, Webster CE. Effects of azole antifungals in vitro on host/parasite interactions relevant to Candida infections. J Antimicrob Chemother. 1988;22(4):473-481.

[23] Vuddhakul V, Mai GT, McCormack JG, Seow WK, Thong YH. Suppression of neutrophil and lymphoproliferative responses in vitro by itraconazole but not fluconazole. Int J Immunopharmacol. 1990;12(6):639-645.

[24] Roilides E, Walsh TJ, Rubin M, Venzon D, Pizzo PA. Effects of antifungal agents on the function of human neutrophils in vitro. Antimicrob Agents Chemother. 1990;34(2):196-201.

[25] Abruzzo GK, Fromtling RA, Turnbull TA, Giltinan DM. Effects of bifonazole, fluconazole, itraconazole, and terbinafine on the chemiluminescence response of immune cells. J Antimicrob Chemother. 1987;20(1):61-68.

[26] Noronha-Blob L, Lowe VC, Otterbein L, Steranka 
L, Burch RM. NPC 15669 reduces mortality associated with sepsis in rats. J Pharmacol Exp Ther. 1993;2(267):664-669.

[27] Lilius EM, Waris MA. Very sensitive and rapid chemiluminescence method for the measurement of phagocytosis. In: Kricka RC, Stanley PE, Thorpe GH, et al, eds. Analytical Applications of Bioluminescence and Chemiluminescence. Orlando, Fla: Academic Press; 1984:401-404.

[28] Khan HA. Zymosan-induced luminol-dependent chemiluminescence response of circulating and extravasated leukocytes in experimental sepsis. Mediators Inflamm. 2004;13(2):123-125.

[29] Mercer-Jones MA, Shrotri MS, Heinzelmann M, Peyton JC, Cheadle WG. Regulation of early peritoneal neutrophil migration by macrophage inflammatory protein-2 and mast cells in experimental peritonitis. J Leukoc Biol. 1999;65(2):249-255.

[30] Frode TS, Ferreira SI, Medeiros YS. Analysis of local and systemic inflammatory responses induced by polymicrobial peritonitis in mice. Mediators Inflamm. 2001;10(5):237-243.

[31] Dunn DL, Barke RA, Knight NB, Humphrey EW, Simmons RL. Role of resident macrophages, peripheral neutrophils, and translymphatic absorption in bacterial clearance from the peritoneal cavity. Infect Immun. 1985;49(2):257-264.

[32] Forman HJ, Torres M. Reactive oxygen species and cell signaling: respiratory burst in macrophage signaling. Am J Respir Crit Care Med. 2002;166(12 pt 2):S4-S8.

[33] Knight JA. Review: free radicals, antioxidants, and the immune system. Ann Clin Lab Sci. 2000;30(2):145-158.

[34] Tauber AI, Babior BM. Neutrophil oxygen reduction: the enzymes and the products. Free Radic Biol Med. 1985;1:265-307.

[35] McCall TB, Boughton-Smith NK, Palmer RM, Whittle BJ, Moncada S. Synthesis of nitric oxide from Larginine by neutrophils. Release and interaction with superoxide anion. Biochem J. 1989;261(1):293-296.

[36] Brestel EP. Co-oxidation of luminol by hypochlorite and hydrogen peroxide implications for neutrophil chemiluminescence. Biochem Biophys Res Commun. 1985;126(1):482-488.

[37] Radi RA, Rubbo H, Prodanov E. Comparison of the effects of superoxide dismutase and cytochrome c on luminol chemiluminescence produced by xanthine oxidase-catalyzed reactions. Biochim Biophys Acta. 1989;994(1):89-93.

[38] Radi R, Cosgrove TP, Beckman JS, Freeman BA. Peroxynitrite-induced luminol chemiluminescence. Biochem J. 1993;290(pt 1):51-57.

[39] Goya T, Morisaki T, Torisu M. Immunologic assessment of host defense impairment in patients with septic multiple organ failure: relationship between complement activation and changes in neutrophil function. Surgery. 1994;115(2):145-155.
[40] Shen SC, Nakao A, Kishimoto W, et al. The ability of polymorphonuclear leukocytes to produce active oxygen in a model of peritonitis in rats. Surg Today. 1993;23(7):603-608.

[41] Oettinger CW, D’Souza M, Milton GV. Targeting macrophages with microspheres containing cytokine-neutralizing antibodies prevents lethality in gram-negative peritonitis. I Interferon Cytokine Res. 1999;19(1):33-40.

[42] Goode HF, Cowley HC, Walker BE, Howdle PD, Webster NR. Decreased antioxidant status and increased lipid peroxidation in patients with septic shock and secondary organ dysfunction. Crit Care Med. 1995;23(4):646-651.

[43] Galley HF, Howdle PD, Walker BE, Webster NR. The effects of intravenous antioxidants in patients with septic shock. Free Radic Biol Med. 1997;23(5):768774.

[44] Martins PS, Kallas EG, Neto MC, Dalboni MA, Blecher S, Salomao R. Upregulation of reactive oxygen species generation and phagocytosis, and increased apoptosis in human neutrophils during severe sepsis and septic shock. Shock. 2003;20(3):208212.

[45] Alonso de Vega JM, Diaz J, Serrano E, Carbonell LF. Oxidative stress in critically ill patients with systemic inflammatory response syndrome. Crit Care Med. 2002;30(8):1782-1786.

[46] Yao YM, Redl H, Bahrami S, Schlag G. The inflammatory basis of trauma/shock-associated multiple organ failure. Inflamm Res. 1998;47(5):201-210.

[47] Bellingan GJ, Caldwell H, Howie SE, Dransfield I, Haslett C. In vivo fate of the inflammatory macrophage during the resolution of inflammation: inflammatory macrophages do not die locally, but emigrate to the draining lymph nodes. J Immunol. 1996;157(6):2577-2585.

[48] Demirbilek S, Ersoy MO, Demirbilek S, et al. Effects of polyenylphosphatidylcholine on cytokines, nitrite/nitrate levels, antioxidant activity and lipid peroxidation in rats with sepsis. Intensive Care Med. 2004;30(10):1974-1978.

[49] Messaris E, Antonakis PT, Memos N, Chatzigianni E, Leandros E, Konstadoulakis MM. Deferoxamine administration in septic animals: improved survival and altered apoptotic gene expression. Int Immunopharmacol. 2004;4(3):455-459.

[50] Paskaloglu K, Sener G, Kapucu C, Ayanoglu-Dulger G. Melatonin treatment protects against sepsisinduced functional and biochemical changes in rat ileum and urinary bladder. Life Sci. 2004;74(9):1093-1104.

[51] Ritter C, Andrades ME, Reinke A, Menna-Barreto S, Moreira JC, Dal-Pizzol F. Treatment with $\mathrm{N}$-acetylcysteine plus deferoxamine protects rats against oxidative stress and improves survival in sepsis. Crit Care Med. 2004;32(2):342-349.

[52] Villa P, Saccani A, Sica A, Ghezzi P. Glutathione 
protects mice from lethal sepsis by limiting inflammation and potentiating host defense. J Infect Dis. 2002;185(8):1115-1120.

[53] Durant R, Klouche K, Delbosc S, et al. Superoxide anion overproduction in sepsis: effects of vitamin $\mathrm{E}$ and simvastatin. Shock. 2004;22(1):34-39.

[54] Heller AR, Groth G, Heller SC, et al. N-acetylcysteine reduces respiratory burst but augments neutrophil phagocytosis in intensive care unit patients. Crit Care Med. 2001;29(2):272-276. 


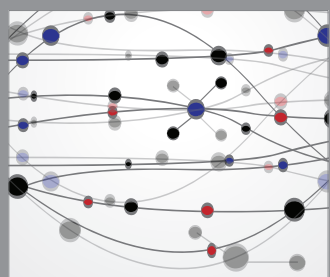

The Scientific World Journal
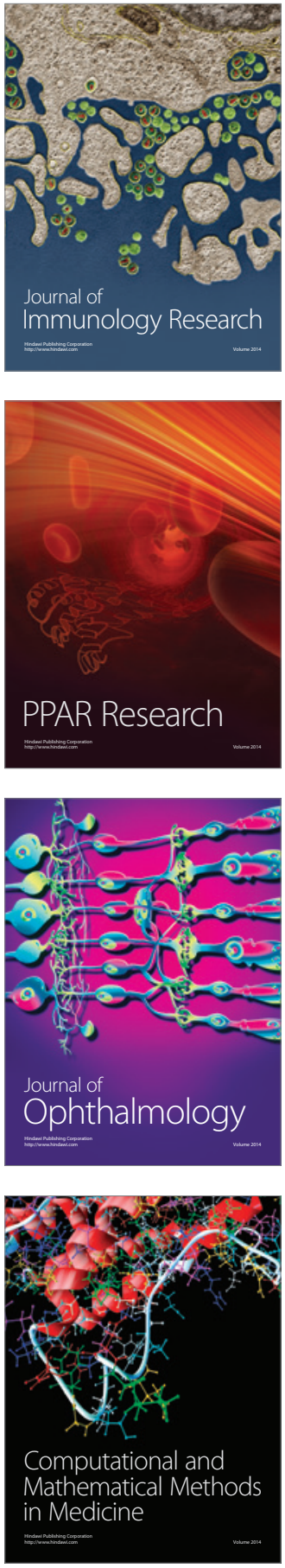

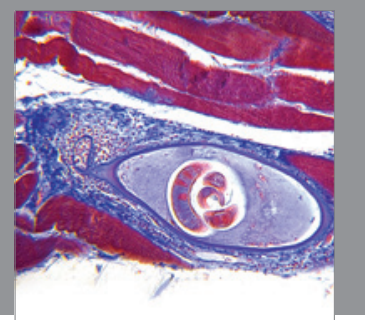

Gastroenterology

Research and Practice
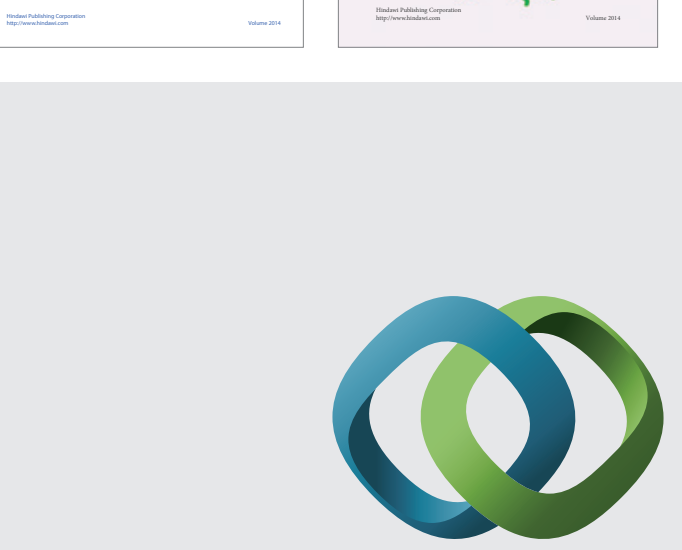

\section{Hindawi}

Submit your manuscripts at

http://www.hindawi.com
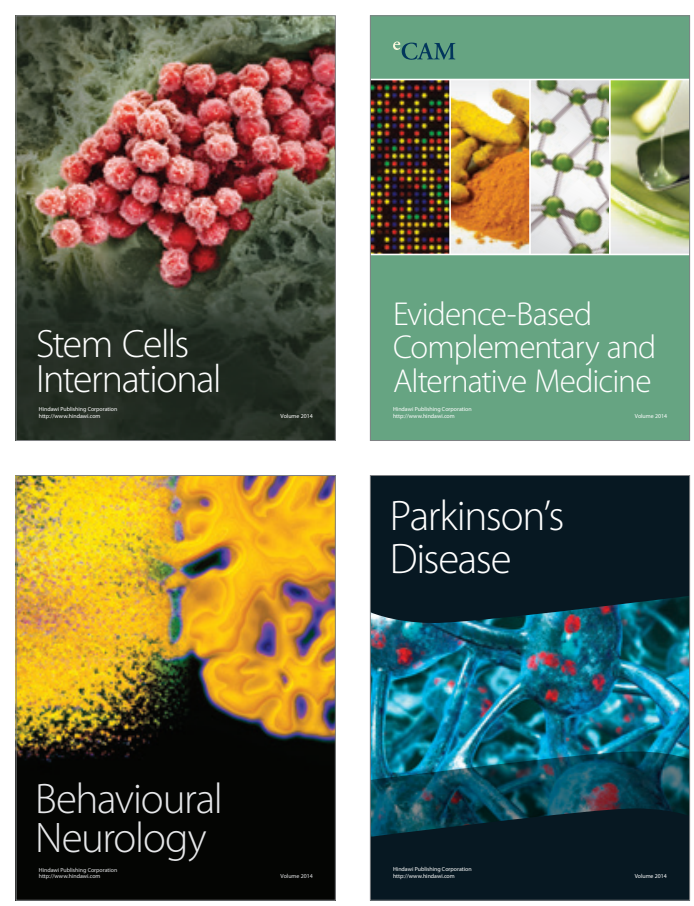

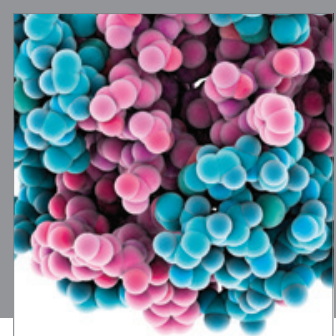

Journal of
Diabetes Research

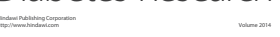

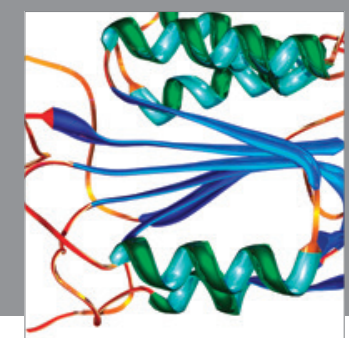

Disease Markers
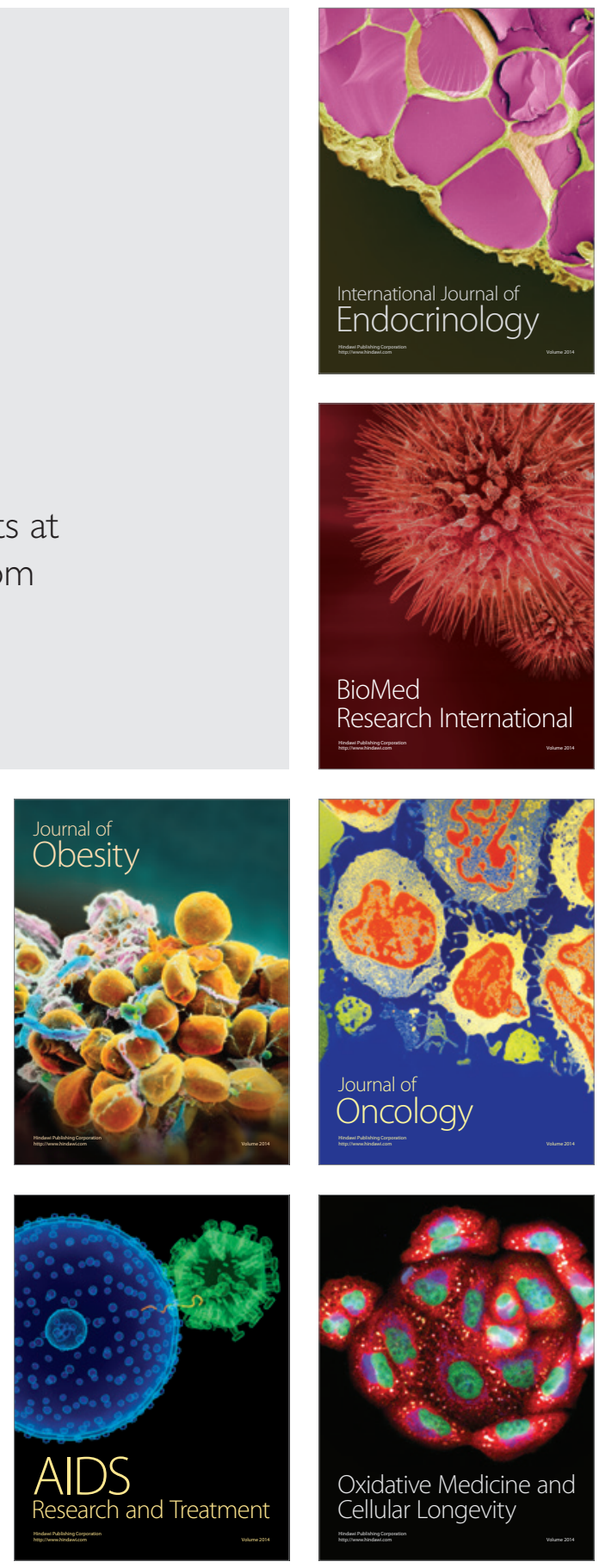